\title{
Communication
}

\section{Vitamin D Receptor Signaling Regulates Craniofacial Cartilage Development in Zebrafish}

\author{
Hye-Joo Kwon \\ Biology Department, Princess Nourah University, Riyadh 11671, Saudi Arabia; \\ xhjkwon@hotmail.com or hjkwon@pnu.edu.sa
}

Received: 21 April 2019; Accepted: 20 June 2019; Published: 22 June 2019

\begin{abstract}
Vitamin D plays essential roles in supporting the skeletal system. The active form of vitamin D functions through the vitamin D receptor (VDR). A hereditary vitamin-D-resistant rickets with facial dysmorphism has been reported, but the involvement of VDR signaling during early stages of craniofacial development remains to be elucidated. The present study investigated whether VDR signaling is implicated in zebrafish craniofacial cartilage development using a morpholino-based knockdown approach. Two paralogous VDR genes, vdra and $v d r b$, have been found in zebrafish embryos. Loss-of- $v d r a$ has no discernible effect on cartilage elements, whereas loss-of- $v d r b$ causes reduction and malformation of craniofacial cartilages. Disrupting both vdra and vdrb leads to more severe defects or complete loss of cartilage. Notably, knockdown of $v d r b$ results in elevated expression of follistatin a (fsta), a bone morphogenetic protein (BMP) antagonist, in the adjacent pharyngeal endoderm. Taken together, these findings strongly indicate that VDR signaling is required for early craniofacial cartilage development in zebrafish.
\end{abstract}

Keywords: Vitamin D receptor (VDR); craniofacial cartilage; zebrafish; follistatin a (fsta)

\section{Introduction}

Vitamin D is known to be involved in mineral homeostasis and the maintenance of a healthy skeleton throughout life [1]. Vitamin D deficiency is the primary cause of congenital rickets [2]. In children with vitamin-D-resistant rickets, craniofacial malformations are often observed [3]. The biological actions of vitamin D can be mediated by vitamin D receptor (VDR)-dependent and -independent pathways [4]. Loss-of-function mutations in the VDR gene cause hereditary vitamin-D-resistant rickets (HVDRR) in infancy [5]. Arita et al. [6] reported a familial HVDRR case with facial dysmorphism associated with homozygosity for a missense mutation in the VDR gene. However, it is not clear whether the VDR mutation itself leads to the craniofacial defects in this case. Several mouse models with targeted ablation of the VDR had been generated [7-10], which displayed different results; in one study, VDR-deficient mice had dysmorphism including a flat face and a short nose [10], but in another study, no facial abnormality was exhibited [8]. Although VDR transcript is nearly ubiquitous [11,12], relatively strong expression of VDR was found in the cartilage chondrocytes of neonatal mouse calvaria, the upper part of the neurocranium [13] and in the developing mandible in 48 hours post-fertilization (hpf) zebrafish embryo [14]. Thus, the role of the VDR signaling in craniofacial development remains unresolved and requires further exploration.

The formation of craniofacial structures is a complex process involving multiple tissue interactions $[15,16]$. Despite morphological differences, the general patterning and genetic network of craniofacial development are highly conserved across vertebrates $[17,18]$. The zebrafish system has been utilized as a valuable animal model for craniofacial research and provided much of our current understanding of craniofacial development [19-21]. In zebrafish, the craniofacial skeleton can be observed as early as 3 days post-fertilization (dpf), which is composed of cartilages later replaced by 
bone [22,23]. The craniofacial cartilages are mainly derived from cranial neural crest cells migrating into the pharyngeal arches and their proper differentiation is regulated by a combination of intrinsic cues and extrinsic signals from surrounding tissues $[24,25]$. The formation of craniofacial structures is controlled by multiple signaling molecules including fibroblast growth factor (FGF), sonic hedgehog (SHH), WNT, Endothelin-1 (Edn1), Notch, and bone morphogenetic protein (BMP) [26-30]. BMP signaling has long been recognized as a key regulator of the craniofacial development [31,32]. BMP ligands are expressed in developing pharyngeal arches $[33,34]$. The pharyngeal endoderm also expresses several BMP antagonists for fine-tuning of BMP activity [35-37]. Perturbation of BMP pathway results in craniofacial defects in mammals and zebrafish [38-40]. Furthermore, BMP signaling interacts with other signaling pathways to regulate dorsal-ventral patterning of the craniofacial skeleton [38,41,42].

The present study reports that VDR signaling is required for craniofacial cartilage formation in zebrafish embryo and downregulates expression of follistatin a (fsta), a BMP antagonist, in the adjacent pharyngeal endoderm for the proper craniofacial cartilage development.

\section{Materials and Methods}

\subsection{Zebrafish Strain, Development, and Staging}

The wild-type strain was derived from the AB line (Eugene, OR, USA). Embryos were maintained in an incubator at $28.5^{\circ} \mathrm{C}$, and staged as described [43]. All protocols for experiments complied with the US National Research Council's Guide for the Care and IACUC-approved Animals Use Protocol number 2012-011.

\subsection{Morpholino Oligomer Injection}

Gene knockdown experiments using antisense morpholino oligomers (MOs) were carried out as previously described [44,45]. Morpholino oligomers (MOs) were obtained from Gene Tools, LLC (Philomath, OR, USA). and diluted in Danieau solution $\left(58 \mathrm{mM} \mathrm{NaCl}, 0.7 \mathrm{mM} \mathrm{KCl}, 0.4 \mathrm{mM} \mathrm{MgSO}_{4}\right.$, $0.6 \mathrm{mM} \mathrm{Ca}\left(\mathrm{NO}_{3}\right)_{2}, 5.0 \mathrm{mM}$ HEPES, $\mathrm{pH}$ 7.6). Zebrafish embryos were injected with $5 \mathrm{ng}$ of each MOs at the one-cell stage. All MOs used here have been validated and reported [44,46,47]. To knockdown $v d r a$, a translation blocker (5'-AACGGCACTATTTTCCGTAAGCATC-3') was used. To knockdown $v d r b$, a splice blocker ( $5^{\prime}$-TCCATCACTAGCAGACGAGGGAAGA-3'), which targets the intron2-exon3 (I2E3) junction was used. In all $v d r b$ knockdown experiments, embryos were coinjected with $p 53 \mathrm{MO}$ to ensure inhibition of nonspecific cell death as described [48]. To assess phenotypes, at least 10 embryos were examined in each experiment. The phenotypes described in this study were completely penetrant. The experiments were conducted at least three times.

\subsection{Alcian Blue Staining and Whole-Mount In Situ Hybridization}

Alcian blue staining was performed as previously described $[45,49]$ with slight modifications. Briefly, embryos were fixed in 4\% MEMFA (0.1 M MOPS pH 7.4, 2 mM EGTA, $1 \mathrm{mM} \mathrm{MgSO}_{4}$, and $3.7 \%$ formaldehyde) and stained in a solution of $0.1 \%$ Alcian blue $/ 70 \%$ ethanol $/ 0.37 \% \mathrm{HCl}$ for 1.5 hours. Samples were destained in $70 \%$ ethanol $/ 0.37 \% \mathrm{HCl}$ and cleared in graded series of glycerol solutions. For photography, whole embryos were placed on depression slides. Whole-mount in situ hybridization analyses were conducted as previously described [45] using probes against foxd3, fsta, and gata3 [50-52]. Briefly, hybridizations were performed overnight at $67^{\circ} \mathrm{C}$ with digoxigenin-labeled antisense riboprobes. Following hybridization, the transcript was detected using an anti-digoxigenin antibody conjugated to alkaline phosphatase and chromogenic substrates nitro blue tetrazolium (NBT)/ 5-bromo-4-chloro-3-indolyl phosphate (BCIP). 


\section{Results}

\subsection{Knockdown of Vdrb Impairs Craniofacial Development in Embryos}

To determine whether VDR signaling is involved in craniofacial cartilage development, loss-of-function experiments were performed using specific morpholino oligomers (MOs). Subsequently, craniofacial cartilage formation was assessed by Alcian blue staining at $4 \mathrm{dpf}$ (Figure 1). In zebrafish, two $V D R$ homologous genes (vdra and $v d r b$ ) are present due to the teleost-specific whole genome duplication [47,53]. In vdra MO-injected larvae (morphants), all craniofacial cartilage elements were intact and appeared almost identical to those seen in wild-type controls (Figure 1A,B,E,F). In contrast, $v d r b$ morphants displayed deficits in craniofacial structures. Knockdown of $v d r b$ resulted in an absence of Meckel's cartilage and palatoquadrate, a significant reduction of ceratobranchials, and a malformation of ceratohyoid and neurocranium (Figure 1C,G). Weak Alcian blue staining in $v d r b$ morphants was further evidence for cartilage hypoplasia. To investigate whether synergistic effects exist between loss-of- $v d r a$ and - $v d r b$, double knockdown was carried out. Remarkably, coinjection of $v d r b \mathrm{MO}$ with vdra MO produced much more severe defects, which led to the loss of almost all craniofacial cartilage elements (Figure 1D,H). These observations indicate that VDR signaling plays a crucial role in craniofacial cartilage development.

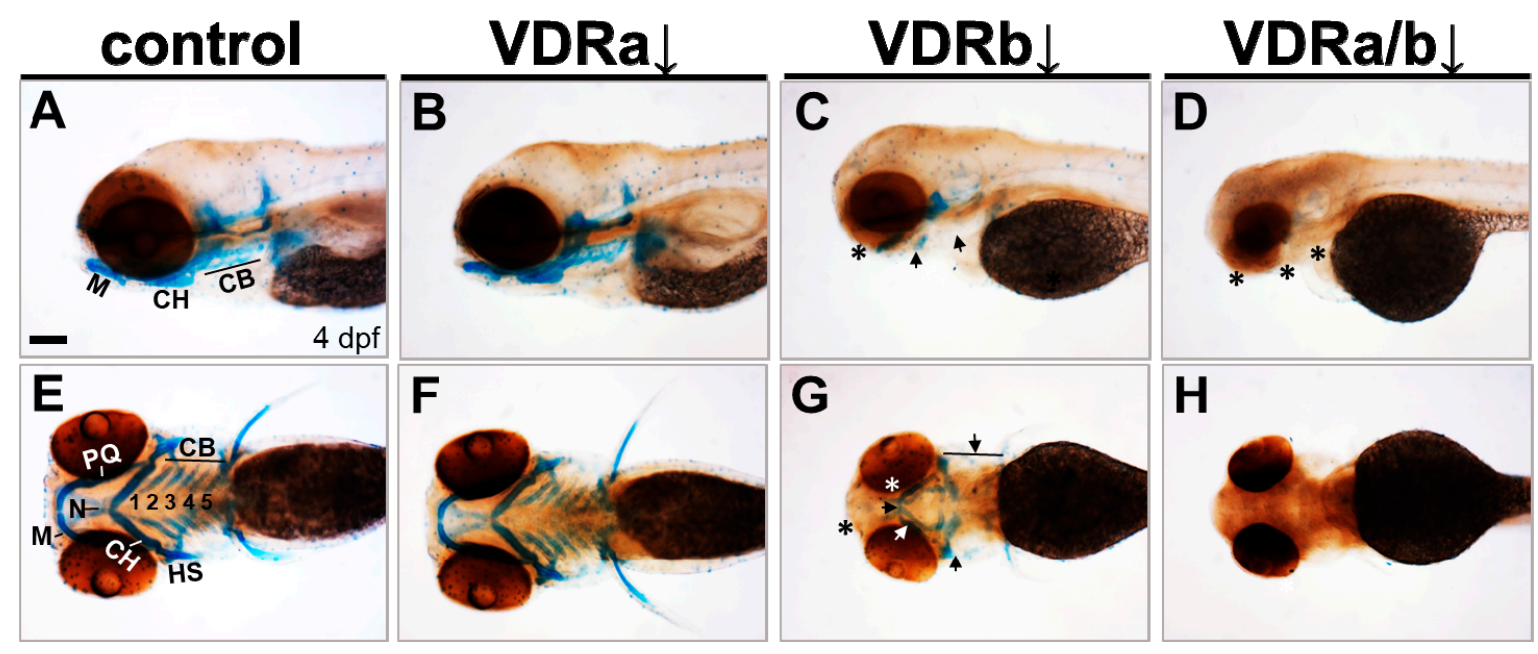

Figure 1. Effects of knockdown of $v d r$ on the craniofacial cartilage development. Craniofacial cartilages were stained with Alcian blue in 4 days post-fertilization (dpf) larvae. (A,E) Wild-type controls. (B,F) vdra morphants. (C,G) vdrb morphants. (D,H) vdra/b morphants. Close-up of head lateral (A-D) and ventral $(\mathbf{E}-\mathbf{H})$ views are shown. Larvae injected with $v d r b$ MO display absence, reduction, and malformations of cartilage components compared to controls or vdra morphants. These phenotypes are completely penetrant and consistent in $v d r b$ morphants. The double knockdown of both $v d r a$ and $v d r b$ leads to more severe defects, complete loss of cartilage. $n \geq 10$ embryos/condition. Scale bars $=100 \mu \mathrm{m}$. Arrows point to reduced or malformed cartilage elements and asterisks denote missing cartilages. M, Meckel's cartilage; $\mathrm{PQ}$, palatoquadrate; $\mathrm{CH}$, ceratohyal; $\mathrm{CB}$, ceratobranchial; $\mathrm{N}$, neurocranium; HS, hyosymplectic.

\subsection{Knockdown of Vdrb Upregulates Fsta Expression in the Pharyngeal Endoderm}

The craniofacial cartilages of the zebrafish develop primarily from cranial neural crest cells [24]. To determine whether knockdown of $v d r$ affected initial neural crest specification, foxd3, the earliest cranial neural crest marker, was examined at $11 \mathrm{hpf}$. All $v d r$ morphants showed normal foxd3 expression in newly specified premigratory neural crest precursors like wild-type embryos, implying that VDR signaling is dispensable for the early cranial neural crest specification. 
BMP signaling is known to play an essential role in differentiation of cranial neural crest cells into the craniofacial cartilages and it has been also suggested that BMP antagonists expressed in the pharyngeal endoderm control BMP activity in craniofacial cartilage precursor cells $[35,38,40]$. To investigate whether $v d r$ knockdown influences BMP signaling, the expression of $f s t a$, a BMP antagonist, in the pharyngeal endoderm was examined at $36 \mathrm{hpf}$ by in situ hybridization. Injection of $v d r a \mathrm{MO}$ alone showed no distinguishable effect on the expression of $f s t a$, which was similar to those in the control embryos (Figure 2A,B). In contrast, embryos depleted of $v d r b$ displayed a dramatic increase of $f s t a$ expression in the pharyngeal endoderm (Figure 2C). In $v d r a / b$ double morphants, both level and domain of $f s t a$ expression were comparable to those in $v d r b$ single morphants (Figure $2 \mathrm{C}, \mathrm{D}$ ). As a control for in situ hybridization, expression of gata3, a BMP-regulated gene in a nonrelevant region was examined (Figure 3). All $v d r$ morphants displayed nearly normal expression levels of gata3 in the posterior part of embryos. Taken together, these results strongly suggest that $v d r b$, not $v d r a$, inhibits $f s t a$ expression in the pharyngeal endoderm to maintain BMP activity during craniofacial cartilage development.
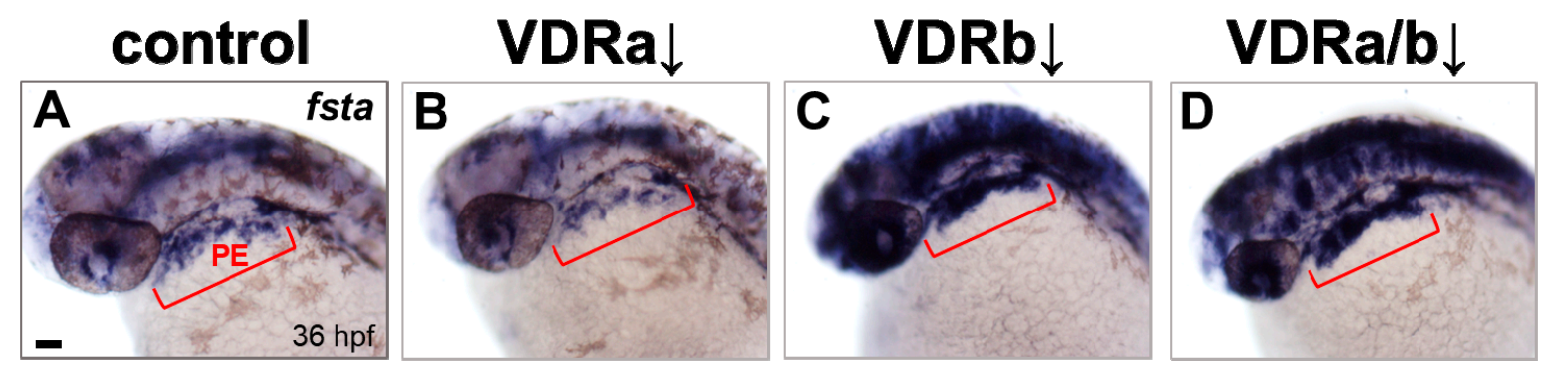

Figure 2. Expression of $f s t a$ in $v d r$ morphants. (A) Wild-type control. (B) $v d r a$ morphant. (C) $v d r b$ morphant. (D) $v d r a / b$ morphant. Expression of $f s t a$ in pharyngeal arches is upregulated in $v d r b$ and $v d r a / b$ morphants. Upregulation throughout much of the brain, eye, and anterior spinal cord was also noticed in the embryos lacking $v d r b$. Images show dorsolateral views with anterior to the left at 36 hours post-fertilization (hpf). Red brackets indicate the domain of pharyngeal endoderm (PE). Scale bars $=50 \mu \mathrm{m}$.

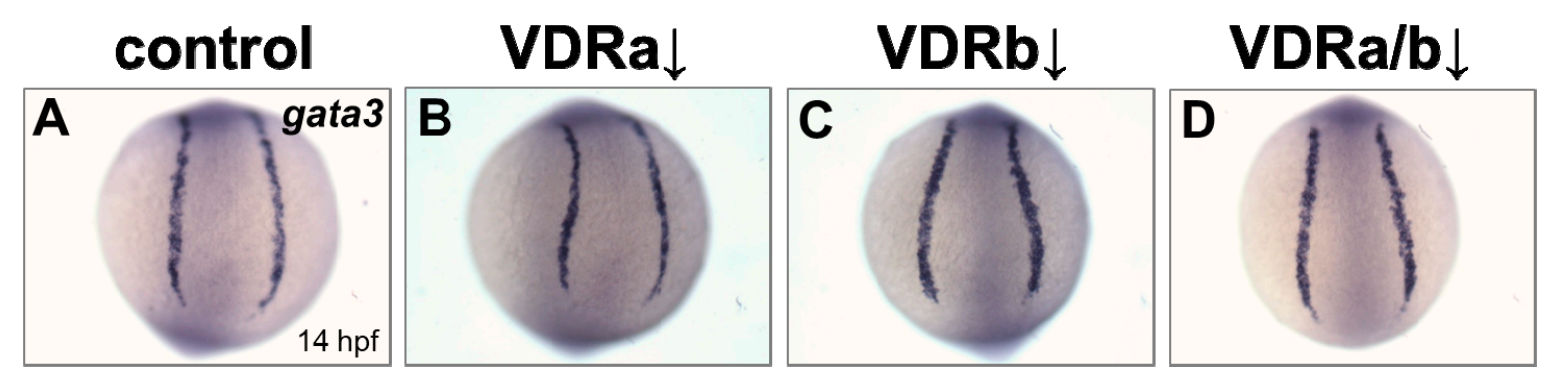

Figure 3. Expression of gata3 in $v d r$ morphants. (A) Wild-type control. (B) vdra morphant. (C) $v d r b$ morphant. (D) vdra/b morphant. Images show posterior views at $14 \mathrm{hpf}$.

\section{Discussion}

Bone is a classic target of vitamin D and the VDR is present in chondrocytes and osteoblasts [13]. Considerable research has been done focusing on the vitamin D/VDR in bone metabolism. However, relatively little is known regarding the role of VDR signaling in skeletal development during embryogenesis. Being a pilot study, the role of VDR signaling in craniofacial cartilage development was examined in this work. To investigate whether loss-of- $v d r$ affects overall gross anatomy of the craniofacial cartilage, Alcian blue staining was applied after the knockdown. For the general evaluation of three-dimensional shapes and sizes of cartilage elements, whole-mounted preparations were more appropriate than flat-mounts in this case. The data presented here clearly demonstrates that VDR 
signaling is required for craniofacial cartilage development and depletion of $v d r b$ leads to severe impairment compared to $v d r a$ knockdown. It has been reported that knockdown of $v d r a$, not $v d r b$, inhibits calcium uptake and leads to delayed ossification of vertebrae [47]. The results of two studies appear to be contradictory, which could be explained by the origin of each skeletal tissue. In zebrafish axial skeleton, craniofacial cartilages mainly develop from cranial neural crest, while vertebrae develop from sclerotome and notochord [54]. It remains possible that two paralogous VDRs may have divergent functions in skeletal development of zebrafish, a teleost [53].

Craniofacial malformations are common structural birth defects and usually caused by perturbations in signaling pathways involved in craniofacial development (reviewed in [55]). BMP signaling pathway plays a crucial role in craniofacial development. It is involved in various processes for craniofacial cartilage development. BMP signaling regulates cranial neural crest cell proliferation, apoptosis, patterning, growth, morphogenesis, and chondrogenic differentiation during craniofacial development $[31,34,41]$. It is also required for the specification of pharyngeal pouch progenitors which are essential for craniofacial skeleton formation [56]. Defects in BMP signaling are associated with cleft lip/palate in mice and human $[57,58]$. The present study, for the first time, shows evidence for a crosstalk between VDR and BMP signaling in craniofacial cartilage development: Loss-of- $v d r b$ upregulates expression of $f s t a$, a BMP antagonist, which may lead to the inhibition of BMP signaling and cause defects in craniofacial cartilages. In zebrafish embryos at $36 \mathrm{hpf}, f s t a$ is expressed in a broad area including brain and eyes (Figure 2). Since the pharyngeal endoderm (PE) plays an important role in regulating craniofacial development, it would be ideal to quantify changes in PE-specific $f$ sta expression using other approach such as qRT-PCR. However, microdissection of PE region for RNA isolation is a bit intricate from the early stage of embryos. In situ hybridization has been routinely used to examine the gene expression level with spatial patterns and to reveal differential regulation of genes following knockdown in zebrafish. In this study, the control and experimental embryos were always processed in parallel and clear overexpression of $f$ sta was detected in the PE of $v d r b$ morphants, relative to controls under this experimental condition. It has been identified that the transcriptional regulator cascade (Runx3/Egr1/Sox9b) in the PE modulates BMP signaling required for craniofacial cartilage formation by reducing the expression of $f_{s} t a$ [35]. Intriguingly, the Runx paralogues possess the potential to interact physically and functionally with the VDR [59]. Taken together, this suggests a molecular mechanism by which VDR signaling participates in craniofacial cartilage development: VDR interacts with Runx in the transcriptional cascade which downregulates the expression of $f s t a$, thereby maintaining proper BMP signaling activity.

Funding: This research received no external funding.

Acknowledgments: The author wishes to thank Bruce B. Riley (Texas A\&M University) for providing zebrafish lab facilities and valuable comments.

Conflicts of Interest: The author declares no conflict of interest.

\section{References}

1. Yoshida, T.; Stern, P.H. How vitamin D works on bone. Endocrinol. Metab. Clin. North Am. 2012, 41, 557-569. [CrossRef] [PubMed]

2. Paterson, C.R.; Ayoub, D. Congenital rickets due to vitamin D deficiency in the mothers. Clin. Nutr. 2015, 34, 793-798. [CrossRef] [PubMed]

3. Roy, W.A.; Iorio, R.J.; Meyer, G.A. Craniosynostosis in vitamin D-resistant rickets. A mouse model. J. Neurosurg. 1981, 55, 265-271. [CrossRef] [PubMed]

4. Willems, H.M.; Van Den Heuvel, E.G.; Carmeliet, G.; Schaafsma, A.; Klein-Nulend, J.; Bakker, A.D. VDR dependent and independent effects of 1,25-dihydroxyvitamin D3 on nitric oxide production by osteoblasts. Steroids 2012, 77, 126-131. [CrossRef] [PubMed]

5. Malloy, P.J.; Eccleshall, T.R.; Gross, C.; Van Maldergem, L.; Bouillon, R.; Feldman, D. Hereditary vitamin D resistant rickets caused by a novel mutation in the vitamin $\mathrm{D}$ receptor that results in decreased affinity for hormone and cellular hyporesponsiveness. J. Clin. Investig. 1997, 99, 297-304. [CrossRef] [PubMed] 
6. Arita, K.; Nanda, A.; Wessagowit, V.; Akiyama, M.; Alsaleh, Q.A.; Mcgrath, J.A. A novel mutation in the VDR gene in hereditary vitamin D-resistant rickets. Br. J. Dermatol. 2008, 158, 168-171. [CrossRef] [PubMed]

7. Erben, R.G.; Soegiarto, D.W.; Weber, K.; Zeitz, U.; Lieberherr, M.; Gniadecki, R.; Moller, G.; Adamski, J.; Balling, R. Deletion of deoxyribonucleic acid binding domain of the vitamin $\mathrm{D}$ receptor abrogates genomic and nongenomic functions of vitamin D. Mol. Endocrinol. 2002, 16, 1524-1537. [CrossRef]

8. Li, Y.C.; Pirro, A.E.; Amling, M.; Delling, G.; Baron, R.; Bronson, R.; Demay, M.B. Targeted ablation of the vitamin D receptor: An animal model of vitamin D-dependent rickets type II with alopecia. Proc. Natl. Acad. Sci. USA 1997, 94, 9831-9835. [CrossRef]

9. Van Cromphaut, S.J.; Dewerchin, M.; Hoenderop, J.G.; Stockmans, I.; Van Herck, E.; Kato, S.; Bindels, R.J.; Collen, D.; Carmeliet, P.; Bouillon, R.; et al. Duodenal calcium absorption in vitamin D receptor-knockout mice: Functional and molecular aspects. Proc. Natl. Acad. Sci. USA 2001, 98, 13324-13329. [CrossRef]

10. Yoshizawa, T.; Handa, Y.; Uematsu, Y.; Takeda, S.; Sekine, K.; Yoshihara, Y.; Kawakami, T.; Alioka, K.; Sato, H.; Uchiyama, Y.; et al. Mice lacking the vitamin D receptor exhibit impaired bone formation, uterine hypoplasia and growth retardation after weaning. Nat. Genetics 1997, 16, 391-396. [CrossRef]

11. Bikle, D.D. Extraskeletal actions of vitamin D. Ann. N. Y. Acad. Sci. 2016, 1376, 29-52. [CrossRef] [PubMed]

12. Goltzman, D.; Hendy, G.N.; White, J.H. Vitamin D and its receptor during late development. Biochim. Biophys. Acta 2015, 1849, 171-180. [CrossRef]

13. Wang, Y.; Zhu, J.; Deluca, H.F. Identification of the vitamin D receptor in osteoblasts and chondrocytes but not osteoclasts in mouse bone. J. Bone Miner. Res. 2014, 29, 685-692. [CrossRef]

14. Craig, T.A.; Sommer, S.; Sussman, C.R.; Grande, J.P.; Kumar, R. Expression and regulation of the vitamin D receptor in the zebrafish, Danio rerio. J. Bone Miner. Res. 2008, 23, 1486-1496. [CrossRef] [PubMed]

15. Twigg, S.R.; Wilkie, A.O. New insights into craniofacial malformations. Hum. Mol. Genet. 2015, 24, R50-R59. [CrossRef]

16. Van Otterloo, E.; Williams, T.; Artinger, K.B. The old and new face of craniofacial research: How animal models inform human craniofacial genetic and clinical data. Dev. Biol. 2016, 415, 171-187. [CrossRef] [PubMed]

17. Green, S.A.; Simoes-Costa, M.; Bronner, M.E. Evolution of vertebrates as viewed from the crest. Nature 2015, 520, 474-482. [CrossRef] [PubMed]

18. Medeiros, D.M.; Crump, J.G. New perspectives on pharyngeal dorsoventral patterning in development and evolution of the vertebrate jaw. Dev. Biol. 2012, 371, 121-135. [CrossRef]

19. Machado, R.G.; Eames, B.F. Using zebrafish to test the genetic basis of human craniofacial diseases. J. Dent. Res. 2017, 96, 1190-1199. [CrossRef]

20. Mork, L.; Crump, G. Zebrafish craniofacial development: A window into early patterning. Curr. Top. Dev. Biol. 2015, 115, 235-269.

21. Weinberg, S.M.; Cornell, R.; Leslie, E.J. Craniofacial genetics: Where have we been and where are we going? PLoS Genetics 2018, 14, e1007438. [CrossRef]

22. Aceto, J.; Nourizadeh-Lillabadi, R.; Marée, R.; Dardenne, N.; Jeanray, N.; Wehenkel, L.; Aleström, P.; van Loon, J.J.; Muller, M. Zebrafish bone and general physiology are differently affected by hormones or changes in gravity. PLoS ONE 2015, 10, e0126928. [CrossRef] [PubMed]

23. Cubbage, C.C.; Mabee, P.M. Development of the cranium and paired fins in the zebrafish, Danio rerio (Ostariophysi, Cyprinidae). J. Morphol. 1996, 229, 121-160. [CrossRef]

24. Knight, R.D.; Schilling, T.F. Cranial neural crest and development of the head skeleton. Adv. Exp. Med. Biol. 2006, 589, 120-133. [PubMed]

25. Schilling, T.F.; Kimmel, C.B. Segment and cell type lineage restrictions during pharyngeal arch development in the zebrafish embryo. Development 1994, 120, 483-494. [PubMed]

26. Clouthier, D.E.; Garcia, E.; Schilling, T.F. Regulation of facial morphogenesis by endothelin signaling: Insights from mice and fish. Am. J. Med. Genet. A 2010, 152A, 2962-2973. [CrossRef]

27. David, N.B.; Saint-Etienne, L.; Tsang, M.; Schilling, T.F.; Rosa, F.M. Requirement for endoderm and FGF3 in ventral head skeleton formation. Development 2002, 129, 4457-4468.

28. Paiva, K.B.; Silva-Valenzuela, M.d.; Massironi, S.M.; Ko, G.M.; Siqueira, F.M.; Nunes, F.D. Differential Shh, Bmp and Wnt gene expressions during craniofacial development in mice. Acta Histochem. 2010, 112, 508-517. [CrossRef] 
29. Walshe, J.; Mason, I. Fgf signalling is required for formation of cartilage in the head. Dev. Biol. 2003, 264, 522-536. [CrossRef]

30. Zuniga, E.; Stellabotte, F.; Crump, J.G. Jagged-Notch signaling ensures dorsal skeletal identity in the vertebrate face. Development 2010, 137, 1843-1852. [CrossRef]

31. Graf, D.; Malik, Z.; Hayano, S.; Mishina, Y. Common mechanisms in development and disease: BMP signaling in craniofacial development. Cytokine Growth Factor Rev. 2016, 27, 129-139. [CrossRef] [PubMed]

32. Nie, X.; Luukko, K.; Kettunen, P. BMP signalling in craniofacial development. Int. J. Dev. Biol. 2006, 50, 511-521. [CrossRef] [PubMed]

33. Holzschuh, J.; Wada, N.; Wada, C.; Schaffer, A.; Javidan, Y.; Tallafuss, A.; Bally-Cuif, L.; Schilling, T.F. Requirements for endoderm and BMP signaling in sensory neurogenesis in zebrafish. Development 2005, 132, 3731-3742. [CrossRef] [PubMed]

34. Liu, W.; Selever, J.; Murali, D.; Sun, X.; Brugger, S.M.; Ma, L.; Schwartz, R.J.; Maxson, R.; Furuta, Y.; Martin, J.F. Threshold-specific requirements for Bmp4 in mandibular development. Dev. Biol. 2005, 283, 282-293. [CrossRef] [PubMed]

35. Dalcq, J.; Pasque, V.; Ghaye, A.; Larbuisson, A.; Motte, P.; Martial, J.A.; Muller, M. RUNX3, EGR1 and SOX9B form a regulatory cascade required to modulate BMP-signaling during cranial cartilage development in zebrafish. PLoS ONE 2012, 7, e50140. [CrossRef]

36. Müller, I.I.; Knapik, E.W.; Hatzopoulos, A.K. Expression of the protein related to Dan and Cerberus gene-prdc-During eye, pharyngeal arch, somite, and swim bladder development in zebrafish. Dev. Dyn. 2006, 235, 2881-2888. [CrossRef]

37. Stottmann, R.W.; Anderson, R.M.; Klingensmith, J. The BMP antagonists Chordin and Noggin have essential but redundant roles in mouse mandibular outgrowth. J. Dev. Biol. 2001, 240, 457-473. [CrossRef]

38. Alexander, C.; Zuniga, E.; Blitz, I.L.; Wada, N.; Le Pabic, P.; Javidan, Y.; Zhang, T.; Cho, K.W.; Crump, J.G.; Schilling, T.F. Combinatorial roles for BMPs and Endothelin 1 in patterning the dorsal-ventral axis of the craniofacial skeleton. Development 2011, 138, 5135-5146. [CrossRef]

39. Bonilla-Claudio, M.; Wang, J.; Bai, Y.; Klysik, E.; Selever, J.; Martin, J.F. Bmp signaling regulates a dose-dependent transcriptional program to control facial skeletal development. Development 2012, 139, 709-719. [CrossRef]

40. Ning, G.; Liu, X.; Dai, M.; Meng, A.; Wang, Q. MicroRNA-92a upholds Bmp signaling by targeting noggin3 during pharyngeal cartilage formation. Dev. Cell. 2013, 24, 283-295. [CrossRef]

41. Alexander, C.; Piloto, S.; Le Pabic, P.; Schilling, T.F. Wnt signaling interacts with bmp and edn1 to regulate dorsal-ventral patterning and growth of the craniofacial skeleton. PLoS Genet. 2014, 10, e1004479. [CrossRef] [PubMed]

42. Barske, L.; Askary, A.; Zuniga, E.; Balczerski, B.; Bump, P.; Nichols, J.T.; Crump, J.G. Competition between Jagged-Notch and Endothelin1 signaling selectively restricts cartilage formation in the zebrafish upper face. PLoS Genet. 2016, 12, e1005967. [CrossRef] [PubMed]

43. Kimmel, C.B.; Ballard, W.W.; Kimmel, S.R.; Ullmann, B.; Schilling, T.F. Stages of embryonic development of the zebrafish. Dev. Dyn. 1995, 203, 253-310. [CrossRef] [PubMed]

44. Kwon, H.J. Vitamin D receptor signaling is required for heart development in zebrafish embryo. Biochem. Biophys. Res. Commun. 2016, 470, 575-578. [CrossRef] [PubMed]

45. Phillips, B.T.; Kwon, H.J.; Melton, C.; Houghtaling, P.; Fritz, A.; Riley, B.B. Zebrafish msxB, msxC and msxE function together to refine the neural-nonneural border and regulate cranial placodes and neural crest development. Dev. Biol. 2006, 294, 376-390. [CrossRef] [PubMed]

46. Kwon, H.J. Vitamin D receptor deficiency impairs inner ear development in zebrafish. Biochem. Biophys. Res. Commun. 2016, 478, 994-998. [CrossRef]

47. Lin, C.H.; Su, C.H.; Tseng, D.Y.; Ding, F.C.; Hwang, P.P. Action of vitamin D and the receptor, VDRa, in calcium handling in zebrafish (Danio rerio). PLoS ONE 2012, 7, e45650. [CrossRef]

48. Robu, M.E.; Larson, J.D.; Nasevicius, A.; Beiraghi, S.; Brenner, C.; Farber, S.A.; Ekker, S.C. p53 activation by knockdown technologies. PLoS Genet. 2007, 3, e78. [CrossRef]

49. Solomon, K.S.; Kudoh, T.; Dawid, I.B.; Fritz, A. Zebrafish foxi1 mediates otic placode formation and jaw development. Development 2003, 130, 929-940. [CrossRef]

50. Odenthal, J.; Nüsslein-Volhard, C. fork head domain genes in zebrafish. Dev. Genes. Evol. 1998, 208, $245-258$. [CrossRef] 
51. Dal-Pra, S.; Fürthauer, M.; Van-Celst, J.; Thisse, B.; Thisse, C. Noggin1 and Follistatin-like2 function redundantly to Chordin to antagonize BMP activity. Dev. Biol. 2006, 298, 514-526. [CrossRef] [PubMed]

52. Neave, B.; Rodaway, A.; Wilson, S.W.; Patient, R.; Holder, N. Expression of zebrafish GATA 3 (gta3) during gastrulation and neurulation suggests a role in the specification of cell fate. Mech. Dev. 1995, 51, 169-182. [CrossRef]

53. Kollitz, E.M.; Hawkins, M.B.; Whitfield, G.K.; Kullman, S.W. Functional diversification of vitamin D receptor paralogs in teleost fish after a whole genome duplication event. Endocrinology 2014, 155, 4641-4654. [CrossRef] [PubMed]

54. Zhang, G. An evo-devo view on the origin of the backbone: Evolutionary development of the vertebrae. Integr. Comp. Biol. 2009, 49, 178-186. [CrossRef]

55. Alvarado, E.; Yousefelahiyeh, M.; Alvarado, G.; Shang, R.; Whitman, T.; Martinez, A.; Yu, Y.; Pham, A.; Bhandari, A.; Wang, B.; et al. Wdr68 mediates dorsal and ventral patterning events for craniofacial development. PLoS ONE 2016, 11, e0166984. [CrossRef] [PubMed]

56. Li, L.; Ning, G.; Yang, S.; Yan, Y.; Cao, Y.; Wang, Q. BMP signaling is required for nkx2.3-positive pharyngeal pouch progenitor specification in zebrafish. PLoS Genet. 2019, 15, e1007996. [CrossRef] [PubMed]

57. Liu, W.; Sun, X.; Braut, A.; Mishina, Y.; Behringer, R.R.; Mina, M.; Martin, J.F. Distinct functions for Bmp signaling in lip and palate fusion in mice. Development 2005, 132, 1453-1461. [CrossRef]

58. Suzuki, S.; Marazita, M.L.; Cooper, M.E.; Miwa, N.; Hing, A.; Jugessur, A.; Natsume, N.; Shimozato, K.; Ohbayashi, N.; Suzuki, Y.; et al. Mutations in BMP4 are associated with subepithelial, microform, and overt cleft lip. Am. J. Hum. Genet. 2009, 84, 406-411. [CrossRef]

59. Marcellini, S.; Bruna, C.; Henríquez, J.P.; Albistur, M.; Reyes, A.E.; Barriga, E.H.; Henríquez, B.; Montecino, M. Evolution of the interaction between Runx 2 and VDR, two transcription factors involved in osteoblastogenesis. BMC Evol. Biol. 2010, 10, 78. [CrossRef]

(C) 2019 by the author. Licensee MDPI, Basel, Switzerland. This article is an open access article distributed under the terms and conditions of the Creative Commons Attribution (CC BY) license (http://creativecommons.org/licenses/by/4.0/). 